University of Nebraska - Lincoln

DigitalCommons@University of Nebraska - Lincoln

USDA National Wildlife Research Center - Staff Publications
U.S. Department of Agriculture: Animal and Plant Health Inspection Service

May 2003

\title{
Cool Temperatures Elicit Reproduction in a Biologically Invasive Predator, the Brown Treesnake (Boiga irregularis)
}

Tom Mathies

USDA-APHIS-Wildlife Services

Lowell A. Miller

Department of Fishery and Wildlife Biology, Colorado State University, Fort Collins

Follow this and additional works at: https://digitalcommons.unl.edu/icwdm_usdanwrc

Part of the Environmental Sciences Commons

Mathies, Tom and Miller, Lowell A., "Cool Temperatures Elicit Reproduction in a Biologically Invasive Predator, the Brown Treesnake (Boiga irregularis)" (2003). USDA National Wildlife Research Center - Staff Publications. 246.

https://digitalcommons.unl.edu/icwdm_usdanwrc/246

This Article is brought to you for free and open access by the U.S. Department of Agriculture: Animal and Plant Health Inspection Service at DigitalCommons@University of Nebraska - Lincoln. It has been accepted for inclusion in USDA National Wildlife Research Center - Staff Publications by an authorized administrator of DigitalCommons@University of Nebraska - Lincoln. 


\title{
Cool Temperatures Elicit Reproduction in a Biologically Invasive Predator, the Brown Treesnake (Boiga irregularis)
}

\author{
Tom Mathies $^{1,2 *}$ and Lowell A. Miller ${ }^{1}$ \\ ${ }^{1}$ U.S. Department of Agriculture, Animal Plant Health Inspection Service, \\ Wildlife Services, National Wildlife Research Center, Fort Collins, Colorado \\ ${ }^{2}$ Department of Fishery and Wildlife Biology, Colorado State University, \\ Fort Collins, Colorado
}

\begin{abstract}
Two different temperature regimes for eliciting reproduction in male and females of the Guam form of the brown treesnake were investigated. Males and females maintained at $24^{\circ} \mathrm{C}$ followed by a 60-day cool period at $19^{\circ} \mathrm{C}$ exhibited substantial reproductive activity, and the females that produced clutches did so during a brief period after return to $24^{\circ} \mathrm{C}$. In contrast, individuals maintained at $28^{\circ} \mathrm{C}$ followed by an identical $19^{\circ} \mathrm{C}$ cooling period exhibited relatively little reproductive activity, and although some females became vitellogenic, none produced eggs. Reproductive activity was virtually absent in all individuals in both groups 7 months after the end of the cool period. Thus, a period of cool temperatures elicits reproductive activity in both sexes and the effect is transitory. Temperatures experienced during the cool period were much lower than the snakes would experience on Guam, and temperatures there are also relatively invariant. Thus, it is possible that only minor fluctuations in temperature are sufficient to elicit reproduction in the Guam population. Because the Guam form does well under, and responds reproductively to, unusually cold temperatures for a lowland tropical reptile, concern that it may have the capacity to invade extralimital temperate areas is warranted. Zoo Biol 22:227-238, 2003. Published 2003 by Wiley-Liss, Inc. ${ }^{\dagger}$
\end{abstract}

Key words: courtship behavior; Guam; introduced species; reptile; temperature

\footnotetext{
*Correspondence to: Tom Mathies, U.S. Department of Agriculture, Animal Plant Health Inspection Service, Wildlife Services, National Wildlife Research Center, 4101 LaPorte Ave., Fort Collins, CO 80522154. E-mail: tom.c.mathies@aphis.usda.gov

Grant sponsor: U.S. Department of Defense, Legacy Program; Grant number: 0079.

Received for publication May 17, 2002; Accepted October 4, 2002.

DOI: $10.1002 /$ zoo.10084

Published online in Wiley InterScience (www.interscience.wiley.com).

${ }^{\dagger}$ This article is a US Government work and, as such, is in the public domain in the United States of America.
}

Published 2003 by Wiley-Liss, Inc. 
INTRODUCTION

The effects of invasive species on native biodiversity is a globally increasing problem that is attracting growing attention [Mooney and Hobbs, 2000]. Oceanic island faunas, because of their relative isolation and inexperience with generalist predators, have been particularly vulnerable when such predators have been inadvertently or purposefully introduced [Vitousek, 1988; Brown, 1989; Case and Bolger, 1991]. Although the presence of predator-naive prey in island systems is certainly a major contributor to the establishment and expansion of an invasive predator, successful reproduction in what is often a novel environment is key. A complete understanding of factors facilitating the establishment of an invasive species therefore requires information on its reproductive biology. This information may in turn provide insights into methods for controlling such invasive species.

A striking example of an invasive generalist predator is the brown treesnake (Boiga irregularis), which underwent an explosive population increase after its introduction to the Pacific island of Guam around 1950 [Savidge, 1987; Rodda et al., 1992]. This rear-fanged, nocturnal colubrid is largely responsible for the extirpation of most of Guam's native terrestrial and aerial vertebrates, including lizards, fruit bats, and virtually all of the island's forest birds [Savidge, 1987; Fritts and Rodda, 1998]. High densities of snakes exist near areas where cargo is loaded for transport by air and sea to other Pacific islands, and recent dispersals have been documented on islands in Hawaii, the Commonwealth of the Northern Mariana Islands, and the continental United States. The population of brown treesnakes on Guam therefore constitutes a substantial threat to the biodiversity of the Pacific region and other potentially inhabitable areas.

Despite the remarkably high densities of brown treesnakes on Guam (50-100 snakes/ha [Rodda et al., 1992]), the relative ease with which they can be collected, the passage of at least 15 years since the problem was first identified, and the substantial body of research accumulated during these years (more than 275 published papers), there is little information on the reproductive biology of this species in captivity or the wild. As far as we know, there have been only two cases of captive reproduction: one female from the subtropical part of the species' range in northeastern Australia produced one clutch of eggs [Barnett, 1993], and, more recently, efforts at Oregon State University resulted in two females of Guam origin producing one clutch of eggs each (M.J. Greene and R.T. Mason, personal communication). Although these contributions add significantly to the information on the captive husbandry and reproduction of this species, no one has yet undertaken a systematic approach to identify the factors that elicit reproduction on a colony-wide basis.

The main focus of our work is the development of chemical methods to control fertility in the brown treesnake. An integral part of this work is the need to evaluate the effects of potential fertility control agents directly on brown treesnakes under laboratory conditions. A captive colony was established at our facilities for this purpose. Here we detail the efficacy of two different temperature regimes for eliciting reproduction in the Guam form of the brown treesnake. We then discuss insights into the possible role of temperature in mediating reproduction on Guam, and the implications of our results for the further dispersal of this species beyond its native range. 


\section{METHODS}

\section{Collection and Husbandry of Snakes}

A group of five males was obtained from the USDA/Monell Chemical Census Center in 1995, where they had been maintained for about 8 months following their collection in Guam. An additional five adult males and 15 adult females were collected in Guam and transported to the National Wildlife Research Center (NWRC) in 2000. Upon their arrival at our facilities, the snakes were housed individually in clear plexiglass cages and randomly assigned to one of two adjoining rooms such that each room contained approximately equal numbers of both sexes. Room A contained five males and eight females, and room B had five males and seven females (the males from Monel were allocated as equally as possible between the rooms). Cage design and dimensions were similar to those described by Greene et al. [1997]. Cage substrate consisted of approximately $8 \mathrm{~cm}$ of Paperchip ${ }^{\circledR}$ compressed, pelletized paper (Canbrands International, Inc., St. Louis, MO). The cages of females contained a hide tube consisting of a $50-\mathrm{cm}-$ long piece of $7.5-\mathrm{cm}-$ diameter PVC tube that was capped at one end. Males were offered one or two freshly-euthanized mice a week and females were offered as many as three. Drinking water was provided ad libitum. The range in body weights of males just before reproduction was elicited (see next section) was 469-1,670 g (mean \pm $1 \mathrm{SE}=1121 \pm 139 \mathrm{~g}$ ); the range in body weights of females was $285-517 \mathrm{~g}$ (mean \pm $1 \mathrm{SE}=398 \pm 15 \mathrm{~g}$ ). Males typically attain much larger body sizes than females [Savidge, 1987]. To minimize disturbance to the snakes, snout-vent lengths were not measured. All work was done according to NWRC study protocol QA-828, and was approved by the NWRC Animal Care and Use Committee.

Two experimental temperature regimes were used, one for each room. The air temperature in room A was about $24^{\circ} \mathrm{C}$, which approximates early-evening air temperatures on Guam [Mathies et al., 2001]. The air temperature in room B was about $28^{\circ} \mathrm{C}$, which is probably more representative of the temperatures experienced by brown treesnakes during the day. We did not have the capability to provide fluctuating day and night temperature regimes, and diel temperature variation in both rooms was negligible. Each room was equipped with a mist system to control humidity within the cages. Room A was equipped with a Mee Fog System ${ }^{\circledR}$ (Mee Industries, Inc., El Monte, CA) to humidify the entire room and the cages within. The cages in room B were humidified by equipping each cage with a mist nozzle and mist line connected to a Pro Mist ${ }^{\mathrm{TM}}$ mist pump (Pro Products, Mahopac, NY). In both rooms the relative humidity inside the cages was maintained at approximately $78 \%$, although there were two periods of reduced humidity (one in each room) due to mister malfunctions. Temperature and relative humidity in each room were recorded hourly using Hobo RH Temp ${ }^{\circledR}$ data loggers (Onset Computer Corporation, Pocasset, MA) suspended inside cages approximately $35 \mathrm{~cm}$ above the cage substrate. Lighting was provided by fluorescent bulbs, and the photoperiod was 12L:12D. Neither room admitted outside light.

\section{Conditions for Eliciting Reproduction}

All snakes were acclimated for at least 250 days under the conditions described above. At the end of the acclimation period (8 January 2001) we initiated a 60-day period of relatively cool temperatures $\left(\sim 19^{\circ} \mathrm{C}\right)$, which approximated the regime used 
by Greene and Mason [2000] to elicit reproductive activity in male brown treesnakes. During this period cage temperatures in rooms $\mathrm{A}$ and $\mathrm{B}$ were cooler by about $5^{\circ} \mathrm{C}$ and $9^{\circ} \mathrm{C}$, respectively. The mean daily temperature and humidity in the cages from just prior to the start of the cool period to 5 June are shown in Fig. 1.

\section{Breeding Trials}

At the end of the cool period, cage temperatures were increased to previous levels, and breeding trials were initiated immediately thereafter (30 March 2001).
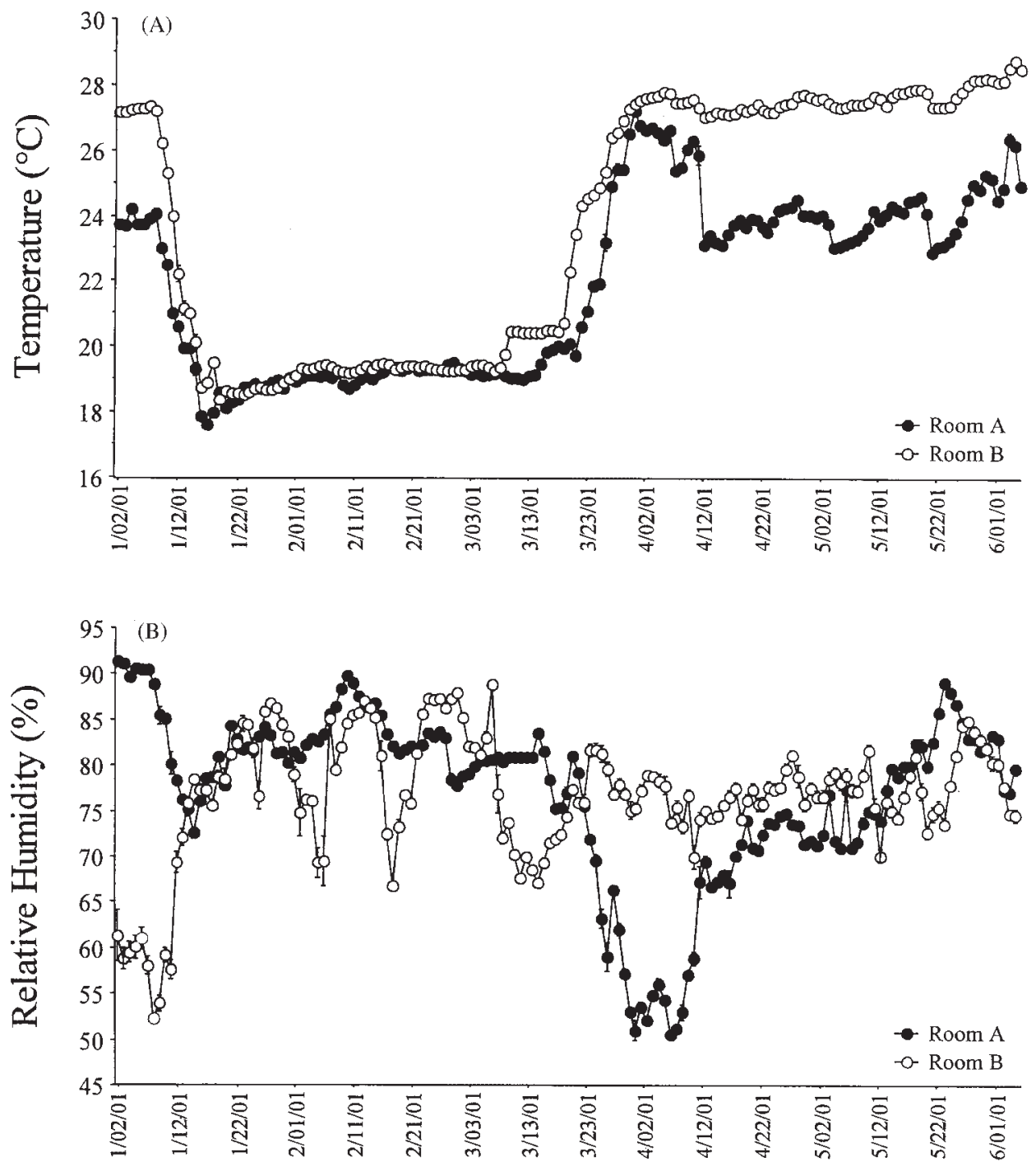

Date

Fig. 1. Environmental conditions in cages of brown treesnakes (Boiga irregularis). A: Daily mean $( \pm S E)$ air temperature. B: Daily mean $( \pm S E)$ relative humidity. 
These trials were conducted during the early-evening hours in near darkness, when brown treesnakes are normally active. Pairs were established by placing a female in the cage of a male. The pair was then observed and filmed using a Sony CCD-TRV58 videocamera equipped with an infrared light emitter (Sony Electronics, Inc., Park Ridge, NJ). The terminology used herein to describe the courtship behaviors of male colubrids was originally developed by Gillingham [1979]. We classified male interest in a female as: 1) "not interested": male is aware of female, but does not chase female; 2) " interested": male chases and dorsally mounts female, but does not perform tail-search copulatory attempts; or 3) "very interested": male chases and dorsally mounts female, and performs tail searches. Each pair was observed for at least $30 \mathrm{~min}$; if the male showed no interest in the female during that time, observations were discontinued. If the male showed interest in the female, observations were made for at least $2 \mathrm{hr}$ or, if they copulated, until the pair had separated. Each female was returned to its cage after its trial.

There were three phases (I-III) to the breeding trials. In phase I, females were paired only with males in their room. Each female was paired with each male at least once (room A: 41 trials total; room B: 35 trials total). Phase I trials were conducted from 30 March to 25 April. Phase II and III trials were designed to further clarify the results obtained in phase I. In phase II we paired each of the males in room A two to three times, each time with a different female in room B (13 trials total). These trials immediately followed the phase I trials (25-30 April). Phase III trials were conducted approximately 7 months after the phase II trails (7-21 December 2001). The males were each paired twice in room $\mathrm{A}$, each time with a different female in their room (10 trials total).

\section{Egg Collection and Incubation, and Hatchling Morphology}

Beginning in early May, the hide tubes of females were opened every 2-3 days to visually assess the reproductive condition of the females and to check for any deposited eggs. Nest boxes containing damp green sphagnum moss as nesting material were placed in cages of females thought to be reproductive, and these were checked for eggs Monday through Friday. Egg clutches were weighed to $0.1 \mathrm{~g}$ on the day they were obtained. Each clutch was placed in a separate plastic box containing moistened vermiculite, which was sealed with plastic kitchen wrap and secured with the cut-out rim of the box lid. The initial ratio of distilled water to dry vermiculite was $0.7: 1.0$. The boxes of eggs were then placed in a Conviron model E7/2 environmental chamber (Controlled Environments, Ltd., Manitoba, Canada), and air temperatures within the chamber (near the eggs) were measured with an Omega HH-25TC thermocouple thermometer (Omega Engineering, Inc., Stamford, $\mathrm{CT})$. The mean temperature $( \pm \mathrm{SE})$ during the period eggs were incubated was $28.1^{\circ} \mathrm{C} \pm 0.03^{\circ} \mathrm{C}$.

Egg boxes were checked for hatchlings 5 days a week. On the day a hatchling was found, it was weighed to $0.1 \mathrm{~g}$, its snout-vent length was measured to $1 \mathrm{~mm}$, and its sex was determined by probing for a hemipene. 


\section{RESULTS}

\section{Male Reproductive Activity: Phase I}

In nearly all trials, the male would increase its rate of tongue flicking and move toward the female within a few minutes of her placement in his cage. Direct tongue flicking of the females' dorsum always preceded any further male mating behaviors. Males in room A showed substantially more interest toward females than did males in room $\mathrm{B}$. Of the 41 breeding trials conducted in room $\mathrm{A}$, male behavior was classified as "very interested" in 21 trials $(51 \%)$ and "interested" in only two trials $(5 \%)$. In contrast, of the 35 trials conducted in room B, male behavior was classified as "very interested" in only four trials $(11 \%)$ and "interested" in five trials $(14 \%)$. In room A, trials categorized as "very interested" were distributed fairly evenly among the five males. Specifically, all males in room A attempted to copulate with females, and did so with similar frequencies. In room B, however, only two of the five males exhibited mating behavior toward females, but these were directed at all but one female.

In all but one case, trials in which the male achieved intromission occurred in room A, and this event was always preceded by behavior classified as "very interested." All five males in room A achieved intromission in at least one trial. For each of these males, the ratio of trials in which intromission occurred to trials in which male behavior was categorized as "very interested" was 1:3, 2:6, 2:4, 3:4, and $4: 4$, respectively. Because there were few trials in which a male was paired with the same female more than once, it so happened that intromission by each male was with a different female each time. However, some females were apparently more attractive and/or receptive to males than others: all five males achieved intromission with one particular female and four males achieved intromission with another. Intromission never occurred with three of the females, despite their apparent attractiveness to males. Intromission occurred in only one trial in room B. Although we do not know whether sperm transfer occurred during copulation, in all cases both the male and female became relatively motionless during this period and regular contractions were observed in the posterior region of the male's abdomen.

\section{Male Reproductive Activity: Phase II}

When it became clear that the males in room B were relatively uninterested in the females, we conducted a further set of trials in an attempt to determine why. Were the males simply not in adequate reproductive condition, or were the females in their room not in adequate condition and therefore unattractive to males, or both? Results from the phase II breeding trials suggest, but do not demonstrate, that the primary reason was that the males were not in adequate breeding condition. Of the 13 breeding trials conducted in phase II, male behavior was classified as "very interested" in six trials (46\%) and "interested" in two trials (15\%). Intromission occurred in one trial. It may have been no coincidence that the female in this particular trial was the same (and only) female that copulated in room B during phase I, and this was one of the few females in room B that developed enlarged ovarian follicles (see Female Reproduction below). These results suggest that most of the males in room $\mathrm{B}$ were not in adequate reproductive condition, and that some of the females in that room were attractive to males known to be in adequate reproductive condition. The reciprocal experiment wherein females in room A with 
proven attractiveness to males are presented to males in room B was not performed, to avoid further disturbance to these females. Because courtship is a dyadic process, and because this experiment was not performed, we cannot be certain of the reproductive state of males in room $\mathrm{B}$.

\section{Male Reproductive Activity: Phase III}

Phase III was conducted to determine whether the males would always attempt to mate with females, even if the females were not in adequate reproductive condition. We found that this was not the case; in these trials male behavior was classified as "interested" in two of the 10 trials, and "not interested" in the remaining eight trials. No intromissions occurred. Thus, the strong interest in females exhibited by these males during phase I (room A) was no longer apparent 7 months later.

\section{Female Reproduction}

Although we did not palpate females to assess their reproductive condition, it was visually apparent while handling them during phase I that at least three females in room B contained either enlarged ovarian follicles or oviductal eggs. However, none of these females produced eggs, and eventually they no longer appeared to be reproductive. We therefore conclude that enlarged follicles (not eggs) had been observed and that these were subsequently resorbed. Only the females in room A produced eggs. Three females in this room produced one clutch of eggs each, and these females were apparently particularly attractive to males. Female CZ17 laid a clutch of eight adherent eggs (70.4 g) in her hide tube (21-23 May) and had copulated with two males during phase I. Female CZ22 laid a clutch of three loose eggs $(25.1 \mathrm{~g})$ in her hide tube (2-4 June) and had copulated with four males during phase I. Female CZ07 laid a clutch of 10 adherent eggs (128.4 g) in her nest box (2-4 June) and had copulated with three males during phase I. Thus, of the 12 cases of intromission by males in room $\mathrm{A}$, nine cases $(75 \%)$ involved these three females. Note that the timing of egg deposition was synchronized among females; all clutches were deposited within a period of 15 days or less. Cage temperatures and husbandry of females have been maintained as they were at the outset of this study, and females have not produced additional eggs to date (April 2002).

\section{Hatching Success and Hatchling Morphology}

One of the eight eggs laid by female CZ17 hatched on August 19 and a second egg hatched 2 days later (incubation period $=87-91$ days). The six remaining eggs did not hatch and dissections revealed they were infertile. Six of the 10 eggs laid by female CZ07 hatched on August 28 and one more hatched the following day (incubation period $=82-86$ days). The three remaining eggs did not hatch and were infertile. None of the three eggs laid by female CZ22 hatched, and all were infertile. All hatchlings appeared normal and healthy. Data on sex and body size are presented in Table 1. 
TABLE 1. Hatchling brown treesnake morphometrics

\begin{tabular}{lcclccc}
\hline \multicolumn{3}{c}{ Female No. CZ17 } & & \multicolumn{3}{c}{ Female No. CZ07 } \\
\cline { 1 - 2 } \cline { 1 - 1 } Sex & Body mass $(\mathrm{g})$ & SVL $(\mathrm{mm})$ & & Sex & Body mass $(\mathrm{g})$ & SVL $(\mathrm{mm})$ \\
\hline Female & 8.17 & 311 & & Female & 9.03 & 343 \\
Male & 8.76 & 314 & Female & 11.22 & 358 \\
& & & Female & 10.45 & 340 \\
& & & Male & 11.07 & 354 \\
& & & Female & 9.65 & 319 \\
& & & Male & 9.62 & 355 \\
& & & Male & 9.73 & 354 \\
\hline
\end{tabular}

\section{DISCUSSION}

\section{Temperature As a Proximate Cue for Reproduction in Captivity}

The results of this study indicate that cool temperatures elicit reproductive activity in both sexes of the brown treesnake. Two lines of evidence support this conclusion for females and males, respectively: 1) egg deposition occurred during a narrow time period following the cool period, and no further clutches have been produced to date; and 2) males in room B were relatively uninterested in females in their room even though these same females were attractive to males in room A. A caveat to the observations on males is that male reproductive behavior was also influenced to a large extent by female reproductive condition: the three females that produced eggs garnered $75 \%$ of the successful matings. Reproductive activity in males is therefore a reasonably good indicator of adequate female reproductive condition. On the other hand, an absence of male reproductive behavior is uninformative; it may indicate inadequate reproductive condition of the male and/or the female. Thus, the results of the phase III trials in which males showed minimal interest in females indicate only that males are not always interested in females.

Our experimental design does not allow us to identify a proximate cue for ovarian development. Although it is possible that cool temperatures alone induce vitellogenesis and ovulation, it is also possible that courtship and mating are also required, as has been observed in at least one other species of colubrid (Thamnophis sirtalis parietalis [Whittier et al., 1987; Mendonca and Crews, 1990]). However, our observation that the females in room B with enlarged ovarian follicles resorbed their follicles suggests that appropriate maintenance temperatures outside of the cool period are necessary for follicular development to continue up through ovulation. Recall that the cool-period temperatures averaged about $24^{\circ} \mathrm{C}$ in room A, but were about $28^{\circ} \mathrm{C}$ in room $\mathrm{B}$. Although $28^{\circ} \mathrm{C}$ is well below the preferred body temperature of the brown treesnake $\left(36^{\circ} \mathrm{C}\right.$ [Johnson, 1975]) and those of most other tropical snake species [Lillywhite, 1987, and references therein], it has been well established that the thermal requirements of reptiles are not constant and often vary with reproductive state [Charland and Gregory, 1990; Mathies and Andrews, 1997]. Furthermore, captive maintenance at a constant high temperature can be deleterious to reproductive processes. For example, constant high temperatures are detrimental 
to testicular and thyroid function in lizards [Wilhoft, 1958; Licht, 1965; Licht and Basu, 1967]. These and other effects on the gonads may be due to temperature altering the responses of tissues to circulating levels of gonadotropins [Licht, 1984].

Factors other than temperature per se may have been responsible for the differences in reproduction we observed between the two rooms. The relatively poor breeding results achieved in room B may have been due to the low humidity these individuals experienced at the outset of the study, although this seems unlikely. It is even less likely that the relatively good breeding results achieved in room A were due to the period of low humidity these snakes experienced at the end of the cool period. In further breeding studies with this colony, where humidity was always maintained at a high level (75-90\%), 14 of the 15 females developed enlarged ovarian follicles following a cool period (Mathies and Miller, unpublished data). It is also unlikely that the difference in female reproduction we observed between the two rooms was due to differences in energy available for reproduction. Although the energy requirements of females in the warmer room $\mathrm{B}$ would have been higher than those in the cooler room A, all of the females maintained good body weight and seemed to be satiated with food each week.

We emphasize that, as far as we know, there was nothing sacrosanct about the temperature regime we used to elicit reproduction. It was chosen simply because a similar regime had been used to successfully elicit reproductive behavior in male brown treesnakes [Greene and Mason, 2000]. Unfortunately, these authors did not specify how their regime was derived. Although it is well established that many species of tropical boids require a lengthy cool period to elicit reproduction [Ross and Marzec, 1990; Walsh, 1994; Tolson, 1994], information on whether cool temperatures similarly influence reproduction in tropical colubrids is lacking. The fact that relatively few of the females (three of eight) in room A produced eggs indicates that a more appropriate temperature regime remains to be determined.

In this study, the hatching success of the eggs we obtained was good, but fertility was not. The reason for the poor fertility is unknown, but may have been due to the inability of the adults to freely regulate body temperature.

\section{Temperature As a Proximate Cue for Reproduction on Guam}

Is there any evidence that temperature acts as a proximate cue for reproduction on Guam? At first approximation, this seems unlikely given that temperatures on Guam are quite equitable throughout the year: mean monthly air temperatures do not vary by more than $3{ }^{\circ} \mathrm{C}$ (monthly range: $24-27^{\circ} \mathrm{C}$ (data from National Oceanic and Atmosphere Administration, National Weather Service)). Moreover, field studies on Guam have not detected any indication of seasonality of reproduction: males with sperm in the ductus deferens and females with enlarged ovarian follicles have been collected in most months of the year [McCoid, 1994] (J.A. Savidge, unpublished data; Mathies and Miller, unpublished data).

Thus, at the population level, it seems unlikely that temperature plays an appreciable role in the timing of reproduction. It may be that temperature elicits reproduction regularly throughout the year, but only in a fraction of the population at any one time. A plausible scenario for females is that brief periods of cool nighttime temperatures (days or weeks, rather than months) occur regularly on Guam and that any of these periods may elicit reproduction, but only in those individuals with sufficient stored energy reserves. In support of this scenario, Jordan 
and Rodda [1994] found that in the period of 1985-1990 females became thinner and less common compared to samples from previous years. They interpreted these findings as evidence of selective ecological stress due to the decline of avian and mammalian prey. Such conditions might tend to disrupt any synchrony in energy accumulation among females. Data for the remainder of this scenario appears to be less supportive: digressions of daily lows below the norm on Guam are quite limited in both magnitude and duration. We obtained air temperature data from the National Climatic Data Center for Guam International Airport $\left(13^{\circ} 29^{\prime} \mathrm{N}, 144^{\circ} 48^{\prime} \mathrm{E}\right)$ for every 2-year interval from 1960 to 1984 (9 years total). For each month we calculated the mean minimum temperature, the longest number of consecutive days in which temperatures fell at least $1^{\circ} \mathrm{C}$ below the monthly mean minimum, and the mean maximum low that occurred within each of these periods. Monthly mean minimum temperatures varied only slightly among months, ranging from about $20^{\circ} \mathrm{C}$ to $23^{\circ} \mathrm{C}$. The number of consecutive days in which temperatures fell at least $1^{\circ} \mathrm{C}$ below the monthly mean ranged only from about 3.0 to 4.5 days for all months except October (5.5 days). The mean maximum lows during these periods ranged from $17^{\circ} \mathrm{C}$ to $18^{\circ} \mathrm{C}$ in January-March, and from $19.0^{\circ} \mathrm{C}$ to $20.5^{\circ} \mathrm{C}$ in the remaining months. Although such digressions of temperature from the norm may seem trivial, it is important to recognize that the reproductive physiology of reptiles is acutely sensitive to even small changes in temperature [Licht, 1972, 1984; Licht and Gorman, 1975]. In addition, there are no data regarding the operative field temperatures available to snakes in Guam, or whether females behaviorally select low body temperatures while they are reproductive. Therefore, the possibility that temperature plays an important role in reproduction by individual females deserves further inquiry.

If we assume temperature is not the primary inducer of reproduction in the Guam population, then what is the origin of this apparently inherent mechanism, as observed in the laboratory? A likely possibility is that the species is reproductively labile and responds facultatively to different climatic conditions. The brown treesnake is a geographically wide-ranging species of probable tropical Australasian origin, and a recent invader of subtropical and temperate climates [Shine, 1991]. As might be expected given such an extensive range, major differences in its reproductive biology exist. Males in Papua New Guinea (tropical), for example, appear to have a nearly continuous testicular cycle [Bull et al., 1997]. In contrast, reproduction in both sexes in eastern Queensland, Australia (subtropical), is strongly seasonal: males are spermatogenic during the cool period (at least January-April) and females undergo follicular development following the cool period (JuneNovember) [Whittier and Limpus, 1996]. Thus, if nothing was known about the origin of the Guam population of brown treesnakes, it would be tempting to speculate that they were of subtropical or temperate origin, given our results. Available evidence, however, suggests that the founder(s) originated from the Admiralty Islands (tropical) north of New Guinea [Rodda et al., 1992]. If so, it is remarkable that none of the individuals in our colony showed any adverse effects (much less reproduce!) from being kept at what would be unusually cold temperatures for most lowland tropical reptiles. Most individuals in our colony continued to feed during the cool period, although intake was substantially reduced (data not presented). The brown treesnakes studied by Bull et al. [1997] in southeastern Queensland (temperate) likely experience even lower temperatures than 
the snakes in our colony: mean minimum air temperatures in this highly seasonal environment ranged from $21^{\circ} \mathrm{C}$ in January to about $10^{\circ} \mathrm{C}$ in July. These observations further support the idea that the brown treesnake can accommodate relatively low temperatures. From a control standpoint, these findings should raise concern that stowaways from Guam could not only inhabit, but also successfully reproduce in colder areas than might be expected, presumably by simply switching to a seasonal pattern of reproduction.

\section{CONCLUSIONS}

1. A period of low temperatures in combination with appropriate temperatures during the maintenance phase elicits reproduction in both sexes.

2. On Guam, brief periods of temperatures only slightly lower than the norm may be the proximate cue for reproduction by females. In captivity, both sexes do well and initiate reproduction when kept at temperatures much lower than those experienced on Guam. These traits may enable the brown treesnake to invade areas previously considered uninhabitable.

\section{ACKNOWLEDGMENTS}

We thank M. Winfree and E. Franklin for their assistance with snake husbandry and the mating trials, and D. Vice and the personnel under his supervision at Andersen Air Force Base, Guam, for collecting most of the snakes used in this study. We also thank R. Engeman, K. Fagerstone, R. Mauldin, and G. Rodda for their helpful comments on earlier drafts of the manuscript.

\section{REFERENCES}

Barnett B. 1993. Breeding the banded brown tree snake, the Nth. Terr. "Night tiger" (Boiga irregularis). Vic Herpetol Soc Monit 5:11-4.

Brown JH. 1989. Patterns, modes and extents of invasions by vertebrates. In: Drake JA, Mooney HA, di Castri F, Groves RH, Kruger FJ, Rejmanek M, Williamson W, editors. Biological invasions: a global perspective. Chichester, UK: Wiley. p 422-77.

Bull KH, Mason RT, Whittier J. 1997. Seasonal testicular development and sperm storage in tropical and subtropical populations of the brown tree snake (Boiga irregularis). Austral J Zool 45:479-88.

Case TJ, Bolger DT. 1991. The role of introduced species in shaping the distribution and abundance of island reptiles. Evol Ecol 5:272-90.

Charland MB, Gregory PT. 1990. The influence of female reproductive status on thermoregulation in a viviparous snake, Crotalis virdis. Copeia 1990:1089-98.

Fritts TH, Rodda GH. 1998. The role of introduced species in the degradation of island ecosystems: a case history of Guam. Ann Rev Ecol System 29:113-40.
Gillingham JC. 1979. Reproductive behavior of the rat snakes of eastern North America, genus Elaphe. Copeia 1979:319-31.

Greene MJ, Nichols DK, Mason RT. 1997. The brown treesnake (Boiga irregularis) as a laboratory animal. Lab Anim 26:28-31.

Greene MJ, Mason RT. 2000. Courtship, mating, and male combat of the brown tree snake, Boiga irregularis. Herpetologica 56:166-75.

Johnson CR. 1975. Thermoregulation in the Papuan-New Guinean boid and colubrid snakes, Candoia carinata, Candoia aspera, and Boiga irregularis. Zoolog J Linnean Soc 56: 283-90.

Jordan MA, Rodda GH. 1994. Identification of sex in Boiga irregularis: implications for understanding population dynamics in Guam. J Herpetol 28:381-4.

Licht P. 1965. The relation between preferred body temperatures and testicular heat sensitivity in lizards. Copeia 1965:428-36.

Licht P. 1972. Physiology and breeding cycles in reptiles: role of temperature. 6th International Symposium on Comparative Endocrinology. Gen Comp Endocrinol 3(Suppl):477-88. 
Licht P. 1984. Reptiles. In: Lamming GE, editor. Marshall's physiology of reproduction. Vol. I. Edinburgh: Churchill Livingston. p 206-82.

Licht P, Basu SL. 1967. Influence of temperature on lizard testes. Nature 213:672-4.

Licht P, Gorman GC. 1975. Altitudinal effects of the seasonal reproductive cycles of male Anolis lizards from Puerto Rico and Virgin Islands. Copeia 1975:496-504.

Lillywhite HB. 1987. Temperature, energetics, and physiological ecology. In: Seigel RA, Collins JT, Novak SS, editors. Snakes: ecology and evolutionary biology. New York: McGraw-Hill Publishing Company. p 422-77.

Mathies T, Andrews RM. 1997. Influence of pregnancy on the thermal biology of the lizard, Sceloporus jarrovi: why do pregnant females exhibit low body temperatures? Funct Ecol 11:498-507.

Mathies T, Felix TA, Lance VA. 2001. Effects of trapping and subsequent short-term confinement stress on plasma corticosterone in the brown treesnake (Boiga irregularis) on Guam. Gen Comp Endocrinol 124:106-14.

McCoid MJ. 1994. Boiga irregularis (brown tree snake) reproduction. Herpetol Rev 25:69-70.

Mendonca MT, Crews D. 1990. Mating induced ovarian recrudescence in the red-sided garter snake. J Comp Physiol A Neuroethol Sens Neural Behav Physiol 166:629-32.

Mooney HA, Hobbs RJ. 2000. Global change and invasive species: where do we go from here? In: Mooney HA, Hobbs RJ, editors. Invasive species in a changing world. Washington D.C.: Island Press. p 425-34.

Rodda GH, Fritts TH, Conry PJ. 1992. Origin and population growth of the brown treesnake, Boiga irregularis, on Guam. Pac Sci 1:46-57.

Ross RA, Marzec G. 1990. The reproductive husbandry of pythons and boas. Stanford, CA: Institute for Herpetological Research. 270 p.
Savidge JA. 1987. Extinction of an island forest avifauna by an introduced snake. Ecology 68:660-8.

Shine R. 1991. Strangers in a strange land: ecology of the Australian colubrid snakes. Copeia 1991:120-31.

Tolson PJ. 1994. The reproductive management of the insular species of Epicrates (Serpentes: Boidae) in captivity. In: Murphy JB, Alder K, Collins JT, editors. Captive management and conservation of amphibians and reptiles. Contributions to Herpetology. Vol. 11. Ithaca, NY: Society for the Study of Amphibians and Reptiles. p 353-7.

Vitousek PM. 1988. Diversity and biological invasions of oceanic islands. In: EO Wilson, editor. Biodiversity. Washington: National Academy Press. p 181-9.

Walsh T. 1994. Husbandry of long-term captive populations of boid snakes (Epicrates, Corallus, and Chondropython). In: Murphy JB, Alder K, Collins JT, editors. Captive management and conservation of amphibians and reptiles. Contributions to Herpetology. Vol. 11. Ithaca, NY: Society for the Study of Amphibians and Reptiles. p 359-62.

Whittier JM, Limpus D. 1996. Reproductive patterns of a biologically invasive species: the brown treesnake (Boiga irregularis) in eastern Australia. J Zool Lond 238:591-7.

Whittier JM, Mason RT, Crews D. 1987. Plasma steroid hormone levels of female red-sided garter snakes, Thamnophis sirtalis parietalis: relationship to mating and gestation. Gen Comp Endocrinol 67:33-43.

Wilhoft DC. 1958. The effect of temperature on thyroid histology and survival in the lizard, Sceloporus occidentalis. Copeia 1958: 265-76. 